\title{
The path less costly
}

\author{
Brady Huggett \\ When faced with a competitive threat, two companies took diametrically opposite approaches. Both were ultimately \\ successful, but Genzyme's decision proved to be the cleaner and cheaper option.
}

$A_{c}^{s}$ the world's leader in developing enzyme-replacement drugs, Genzyme has always understood the importance of first to market. In 1991, the company obtained approval for Ceredase (alglucerase injection), an enzyme replacement therapy for lysosomal storage disease (LSD) type 1 Gaucher. Three years later, its second-generation product, Cerezyme (imiglucerase for injection), was also cleared for commercialization. The lack of treatments for lysosomal storage diseases and effective patient outreach and marketing meant that Genzyme could command soaring prices for its orphan treatments. In 2000 , the two drugs alone provided $66 \%$ of Genzyme's entire product revenue.

At this time, Novazyme Pharmaceuticals was a young company developing a preclinical product for another lysosomal storage disease called Pompe. Its patented phosphotransferase technology was designed to add mannose- 6 phosphate and $N$-acetylglucosamine sugars to recombinant $\beta$-glucocerebrosidase produced in Chinese hamster ovary $(\mathrm{CHO})$ cells, thus increasing uptake of the enzyme in the patient. The idea was that less drug would be needed per patient, and any eventual product would be priced lower than competitors, although approval lay some years away.

By June 2001, however, the company was in financial trouble: it had about $\$ 5.5$ million in cash and equivalents, with no incoming revenue and a six-month burn of $\$ 11.9$ million. The company needed help if it was to handle the expense of clinical trials.

There was interest from Genentech, which offered a collaboration, including \$30 million upfront, milestone payments and 50\% of any sales. But Genzyme, which had its own product in development for Pompe, wanted more than a partnership. It offered to buy the company outright for \$137.5 million, pegging another \$87.5 million on milestones surrounding approval of one or more drugs that incorporated Novazyme's platform technology.

Genzyme was already conducting an extension of a phase 2 trial with transgenically derived human alpha-glucosidase for Pompe disease, and also a phase 2 trial of a CHO cell-derived alpha-glucosidase product in-licensed from Synpac, of Research Triangle Park, North Carolina, for the same indication. It also had its own, internally developed compound for Pompe. By taking Novazyme's drug in house, Genzyme could line it up against its three candidates in a massive preclinical trial and move the best one forward based on results.

Ultimately, the best replacement protein turned out not to be Novazyme's drug; worse still, the data surrounding the technology platform proved to be nonreproducible. It seemed the buyout was a bust all-round.

But consider another company's dance with a potential competitor: Genentech of S. San Francisco, Calif. and its twisting history with Tanox

Brady Huggett is Business Editor at Nature Biotechnology. and Novartis of Basel. Houston-based Tanox was founded in 1986 to focus on anti-IgE antibodies and by 1989 was looking for a clinical development partner; it sent samples of its candidate to both Genentech and Ciba Geigy (the company that would later become Novartis). Genentech passed. Ciba Geigy, however, began working with Tanox on anti-IgE antibodies for allergic diseases.

Yet Genentech clearly had interest in the area, because it began its own anti-IgE program a few years later-a move that prompted a misappropriation suit from Tanox. The companies fought in court for three years before Genentech, Tanox and Novartis reached a settlement and entered a cross-licensing agreement for anti-IgE antibodies.

That was hardly the end for Genentech. After the three companies surveyed their collective R\&D efforts and pushed Genentech's anti-IgE product (eventually called Xolair; omalizumab) to the front, Tanox took it upon itself to develop its discarded anti-IgE antibody (TNX-901) for peanut allergy, thinking that well within the rights of the original three-way contract. Tanox's partners did not see it the same, and the trio went back to court to settle matters, with Tanox eventually receiving \$6.6 million in 2004 with the stipulation it let TNX-901 die.

Nor was this the end. Xolair was approved in 2003 for asthma, and has gone on to sell well: it approached blockbuster status in 2009 and through last year has sold about $\$ 3.3$ billion worldwide. Tanox had a slice of sales through the cross-licensing agreement, which became the impetus for Genentech to approach Tanox in December 2005 with a merger offer. The deal was announced in November 2006 at $\$ 919$ million, a 46\% premium to Tanox's stock price pre-announcement. One can only wonder what the merger would have cost Genentech 16 years before, when Tanox first came knocking. Instead, Genentech rebuffed that initial proposition and went to court with Tanox twice before finally swallowing it in a move that had more to do with accounting than science or patients.

In either of these mergers, the gem compound eventually died-hardly a surprise, given the rates of attrition in drug pipelines. At the same time, both of these buyouts could technically be called a success.

Bringing aboard Novazyme and its product temporarily muddied the waters for Genzyme, but it knew that whatever eventually floated to the top, it would own. The acquisition crisply and cleanly removed a noisy competitor, leaving Genzyme to focus on approval: Myozyme was cleared in 2006 and has since surpassed \$1 billion in worldwide sales. The numbers worked out fine for Genentech, too-the Xolair revenue slice pays for the price of Tanox-but the company wasted resources and money in court and ended up paying more than it might have. It also received negative press for its court fight over Tanox's attempts to develop a peanut allergy drug. Crisp and clean this was not. 